\title{
La competencia mediática como forma de análisis de la realidad transmitida
}

\section{Media competence as a form of analysis of the transmitted reality}

\section{Mari Carmen Caldeiro Pedreira- Universidad Técnica del Norte, Ibarra - mariccaldeiro@yahoo.es}

Patricia de Casas Moreno - Universidad de Huelva - patricia.decasas@alu.uhu.es

\section{Resumen}

El nuevo ecosistema comunicativo está caracterizado por la proliferación de una ingente cantidad de pantallas que reflejan la realidad de forma mediatizada. Los contenidos audiovisuales se conciben como mercancías, que se difunden según unos intereses concretos y con un fin determinado por parte de las grandes empresas de comunicación. Sin duda, el consumidor está expuesto a una sobreabundancia informativa donde los valores no corresponden con los deseables, la programación televisiva, las redes sociales, los videos juegos y la publicidad son los encargados de conformar la mirada y actitud del receptor e interfieren en sus emociones. El presente trabajo trata de explicar la actual realidad mediática basándose en los múltiples medios de comunicación que existen -tradicionales o modernos- y su fácil acceso. En la era multipantalla Internet y los pequeños dispositivos cobran mayor fuerza permitiendo el acceso a la información segmentada y actualizada al instante. Por tanto, proponemos, la necesidad de desarrollar la competencia mediática como forma de obtención de la conciencia crítica del «prosumer».

\section{Palabras clave}

Competencia mediática, ecosistema comunicativo, conciencia crítica, realidad transmitida, alfabetización mediática, multipantallas.

\section{Abstract}

The new communication ecosystem is characterized by the proliferation of a large number of screens that reflect reality in a mediated way. Audiovisual content are conceived as goods, which are disseminated according to specific interests and purposes determined by the large media companies. Certainly, the consumer is exposed to an overabundance of information where the importance of the values do not correspond with the desirable due to the emotional charge that creates television programming, social networks, video games and advertising as responsible for shaping the look and attitude of the receiver. This paper attempts to explain the current media reality based on multiple media that exist -traditional or modern- and easy access to them as it is the case of the Internet and the era "Multiscreen», where small devices gain greater use for access to segmented and daily updated information. On the other hand, we will address the need to develop media competence in order to explain the dimensions related to the implementation of a proper critical awareness by the viewer through the media in this new ecosystem post media.

Keywords

Media competence, communication ecosystem, critical awareness, actually transmitted, Media literacy, multiscreens.

Sumario

1. Introducción. 2. La veracidad como forma de expresión de la realidad mediática. 3. La competencia mediática como forma de expresión social. 4. El desarrollo de la conciencia crítica en el ecosistema comunicativo. 5. Discusiones y conclusiones. 6. Bibliografía. 


\section{Introducción}

El presente trabajo busca plantear qué interferencias se producen entre los medios de comunicación tradicionales y los medios de comunicación modernos como es el caso de Internet. Asimismo, centra el interés en ahondar en el consumo mediático que la audiencia realiza y la realidad representada y difundida por los medios que conforman el ecosistema digital más reciente. Tras los múltiples desarrollos producidos en este entorno llaman la atención de forma especial los nuevos contenidos y los «nativos digitales», definidos como aquel sector de la población que interacciona con las tecnologías sin impartir lecciones previas sobre ellas. Se trata de un conjunto de sujetos que no solo han nacido sino que desarrollan su vida en la era de las «Multipantallas» que ocupa un lugar destacado en la investigación que se presenta.

El desarrollo incesante de la tecnología está provocando en los medios de comunicación múltiples transformaciones, sobre todo, en el medio televisivo que ha pasado de Neotelevisión a Postelevisión. En este sentido, un nuevo ecosistema digital cobra vida en un contexto en el cual la abundancia informativa, la personalización de la oferta, la convergencia y la interactividad se identifican con algunos de los puntos fuertes más relevantes. En este contexto, la Postelevisión genera una gran interacción entre los consumidores, quienes ante la ingente oferta de contenidos consumen cualquier tipo de información eludiendo posibles criterios de elección. A esta forma de soslayarlos contribuyen las «Multipantallas» (teléfonos móviles, Tablet, ordenadores portátiles, ipods, etc) desde donde el usuario puede acceder y elegir los contenidos más afines a sus necesidades creando un modelo de vida digital más moderno y acorde con las necesidades que a diario van surgiendo.

La revolución del sector de la comunicación y los medios ha provocado la ruptura con las formas tradicionales de creación, difusión y recepción audiovisual y al mismo tiempo, ha suscitado la delimitación de cinco nuevos puntos frente al desarrollo de este ecosistema: la democratización digital, la adecuación de los contenidos audiovisuales al nuevo entorno tecnológico, la búsqueda de nuevas formas de financiación frente a la futura inexistencia del modelo tradicional, la búsqueda de la calidad informativa y la protección del público infantil (Vecino, 2010: 26).

A lo largo de la historia, la televisión ha sido y continúa siendo el medio de comunicación de masas por excelencia. Por otra parte, desde su aparición en los años 90 la información se vio mercantilizada por las grandes empresas comunicativas, interesadas más en los beneficios aportados por el medio que por la calidad de los contenidos para la audiencia. Actualmente, este problema está afectando a todos los medios de comunicación, incluso al nuevo ecosistema digital, donde proliferan una incesante cantidad de pantallas con múltiples informaciones cuyo único fin es ser consumidas. Esta decadencia informativa ha generado cambios en los criterios de noticiabilidad e incluso en la creación de un nuevo género llamado «infoentretenimiento», donde prima el hecho noticioso y la espectacularización del mismo (Gutiérrez, 2011: 8).

Como consecuencia de la revolución digital estamos frente a una situación compleja que dificulta el establecimiento de una clara distinción entre el mundo de los media: el mundo la comunicación, el de la cultura de masas y la publicidad centrando su interés en el valor de la información como una mercancía; un valor que las empresas se encargan de institucionalizar como principal y básico (Ramonet, 2002).

En otro ámbito, la familia y las pantallas siempre han sido el eje central de todo hogar; y le permiten al usuario escoger la información «a la carta»; sin embargo, esto no implica que se conviertan en prosumidores dado que no siempre desarrollan las habilidades mínimas que les permiten analizar y comprender aquello que aleatoriamente eligen. La actuación de los usuarios se desarrolla en un espacio de convergencia e interactividad y en la mayor parte de las ocasiones posee un único fin: crear una conversación de discurso poliédrico y en forma de red, es decir, red de amigos, de seguidores, etc. (Alonso \& Raigada, 2014: 2).

Desde la perspectiva Mcluhaniana se confirma la evolución del ecosistema mediático debido a los nuevos desarrollos tecnológicos (Canavilhas, 2011: 14). Sin duda, con la aparición de Internet el acceso a la información, así como al entretenimiento han suscitado un gran interés por parte de los consumidores frente a los medios de comunicación tradicionales, cuyos contenidos se convierten, en cierta medida, en formatos caducos.

A pesar de que los medios de comunicación tradicionales, que conforman la «sociedad mediática de masas», son considerados el eje central de la mediación social, de la difusión de la información y el conocimiento y del impulso democrático, los avances de las recientes Tecnologías de la Información y la Comunicación (TIC) han incorporado, al mismo tiempo, nuevas herramientas y formas de intermediación e interactividad que están provocando la reconfiguración del actual espacio mediático (Campos-Freire, 2008). Por lo tanto, este desarrollo hacia una sociedad más digitalizada y en constante actualización informativa nos sitúa en una sociedad postmediática, donde la información es más segmentada, acelerada, personalizada, convergente, transparente, interconectada y aproximada a la colaboración y participación.

Tras la aparición de Internet el equilibrio que existía entre los medios de comunicación ha quedado obsoleto. Según Camon-Alves, «estamos pasando de los medios de masas a la masa de medios. Pasamos del sistema media-céntrico al yo-céntrico, donde el individuo se transforma en un microorganismo al tener el poder de comunicarse, de intercambiar información, de redistribuir, de mezclar cosas, de hacer sus propios vídeos y colgarlos para que los vean miles de personas» (Elola, 2010). Asistimos a una nueva reconfiguración mediática donde las tecnologías digitales adquieren un rol predominante frente a otros medios de comunicación. Por su parte, Rainie y Wellman (2012) indican que estos cambios que se han producido en la sociedad contemporánea son definidos como una «triple revolución», cuyos instrumentos esenciales son Internet, las redes sociales y la comunicación móvil.

Por otro lado, la sobreabundancia informativa se erige como otra de las características fundamentales de este ecosistema. Esto se debe, en buena medida, a la creciente implantación de las tecnologías digitales entre los ciudadanos. Por lo tanto, esta necesidad de estar siempre informado y de acceder a los dispositivos digitales provoca lo que conocemos como «obesidad informativa» (Puche, 2013: 164). Una obesidad que deriva en la incapacidad para digerir cantidades de información sin calidad y que presenta un problema candente; un inconveniente centrado principalement que en la dificultad de encontrar un modelo eficaz, en esta "era de la hiperconectividad», un modelo capas de gestionar la sobreabundancia informativa a la que diariamente se enfrentan los ciudadanos. 
Según Toffler (1972), esta sobrecarga se convierte en un perjuicio específico derivado de este nuevo contexto social donde el individuo carece de las herramientas y habilidades necesarias para asimilar la sobreabundancia de información. Desde que Toffler abordara esta cuestión, múltiples son los autores que han definido este problema denominando a este concepto con acepciones como: «nube tóxica de datos» (Shenk, 1997), «infoxicación», (Cornella, 2008), «infopolución» (Bray, 2008), «diluvio de información» (Gleick, 2011); «infoglut» (Andrejevic, 2013).

Unas acepciones y otras justifican la necesidad de reconsiderar la adopción de una postura crítica frente al consumo incesante de información a través de las nuevas tecnologías digitales, tecnologías que están desarrollando una fuerte dependencia entre el consumidor y el instrumento digital.; una dependencia que puede atribuírsele a diferentes factores: en primer lugar los intermediáticos relacionados con el estudio de los medios y sus relaciones; por otro lado, los contextuales centrados en el estudio del espacio y de la forma de consumo, es decir, la movilidad y la descentralización como elementos claves; y por último, los tecnoambientales que estudian las interfaces y la acción del consumidor en el ecosistema relacionados con las nuevas aplicaciones y programas que generan nuevas interacciones con los medios de comunicación (blogs y redes sociales). Unos y otros certifican la necesidad de estudio de su uso y sus condicionantes en el individuo (Canavilhas, 2011: 16).

En conclusión, la aparición de las nuevas tecnologías implica un cambio permanente en los conceptos de alfabetización y las competencias básicas concebidas como herramientas que ayudan a entender el nuevo ecosistema digital. En este sentido, surge la necesidad incesante de estar alfabetizados digitalmente para conseguir la capacidad global, por parte de los individuos, que les permite no solo consumir sino además, producir cualquier tipo de información uniendo la tecnología y los conocimientos de cada individuo.

La digitalización ha generado que la comunidad científica haga especial hincapié en el análisis del estudio de las nuevas formas de comunicación. El interés por saber usar un ordenador correctamente es una necesidad evidente en el mundo de la escuela y la educación, consiguiendo de este modo, que el término de alfabetización mediática cobre mayor fuerza para conseguir entender todos los nuevos procesos digitales, que están apareciendo a través de los múltiples aparatos electrónicos. En este sentido, la alfabetización ha generado dos campos de estudio: por un lado, aquellos que se centran en la alfabetización mediática y forma a los individuos con las suficientes competencias digitales, y por otro lado, los que se interesan por la incorporación de las nuevas tecnologías en los procesos de enseñanza y educación (García et al, 2014: 4).

La demanda de alfabetización justifica el surgimiento de conceptos como, «transliteracy» definida como la convergencia de alfabetizaciones o "prosumidores», es decir, sujetos capaces de asumir y procesar contenidos audiovisuales de forma autónoma y crítica. Este nuevo concepto se vincula al desarrollo de múltiples habilidades de escritura y conocimientos de las plataformas que le permiten la creación de sistemas de conocimientos para la sociedad (Giones-Valls, 2010: 35).

\section{La veracidad como forma de expresión de la realidad mediática}

En el contexto descrito, la educación mediática supone el eje fundamental para el alcance del pensamiento crítico de las personas, así como para la percepción y compresión del consumo de las informaciones. Los medios de comunicación se han convertido en agentes socializadores y modeladores de pautas y conductas de comportamientos a la hora de interpretar la realidad social. Según Correa, Guzmán \& Aguaded (2000: 26-30), las características de los medios de comunicación a la hora de socializar a la ciudadanía se corresponden con:

-La objetividad y la manipulación inadvertida, donde los mensajes son una construcción social contingente ligada a unos intereses particulares cargados de manipulación y diversas formas de control social.

- La recreación de los estereotipos, que generan representaciones de la realidad que la audiencia consume como reales.

-La hiperestimulación audiovisual y el conocimiento fragmentado.

-La pasividad y aislamiento de la realidad virtual

-La información, apertura y alineación.

-La primacía de la imagen sobre el texto, es decir, la búsqueda de emociones a través de las imágenes.

El ecosistema mediático ha vivido un constante cambio debido a la inserción de nuevos dispositivos tecnológicos restándole valor a los medios tradicionales así como a sus modelos de financiación. Actualmente, las relaciones personales están orientadas a la participación y la producción de contenidos debido al nuevo sistema mediático basado en la interactividad y la convergencia de las nuevas Tecnologías de la Información y la Comunicación (TIC); por lo tanto, estas nuevas prácticas generan constantes desafíos en el mercado mediático debido a la circulación y producción de la información. En este sentido, las nuevas formas de recepción de la información generan cambios, en el consumo (Fernández, 2013: 68).

Como hemos indicado, una de las características principales de esta sociedad contemporánea es la multiplicación de los dispositivos tecnológicos alterando las relaciones de producción, reproducción y transmisión de la información, que sin duda, produce una «transmedialidad» en la difusión y recepción por parte de la audiencia transformando a los medios de comunicación en dispositivos tecnológicos simultáneos (Fernández, 2013: 77).

El desarrollo de la era «Multipantallas» provoca que Internet enlace a millones de personas en nuevos espacios, cambiando la forma de pensar de los espectadores. Todo ello se apoya en diferentes hipótesis, entre las que adquieren una relevancia fundamental el hecho de que las pantallas se hayan convertido en un elemento asiduo en los entornos artificiales de la vida humana cambiando los modos de ver tradicionales. Asimismo, las condiciones de uso de éstas están creando marcos prácticos desde el punto de vista pragmático y desde el punto de vista de los usos del discurso; por otras parte surgen nuevos servicios audiovisuales más competitivos relacionado con el aumento de horas que los ciudadanos consumen información (Pérez-Tornero, 2008: 16).

Retomando ideas anteriores, la televisión siempre ha sido el medio de comunicación más conectado con el escaparate de la realidad 
debido a que a través del espejo mediático se conocían los acontecimientos sociales más importantes del momento. Sí bien, no permite la creación de contenidos como los medios actuales, de igual modo construye la realidad basándose en los sentimientos y las motivaciones de los espectadores. Una realidad que presenta de la forma más sensacionalista e impactante con el único fin de conseguir beneficios y que el consumo de la información crezca frente a la competencia. Este tipo de informaciones se constituyen como representaciones válidas, sin embargo, no hay que olvidar que lo que aparece en la pantalla no es realidad.

Ante la realidad social existente surge la necesidad de poner en evidencia a los medios de comunicación, así como a los medios audiovisuales a la hora de transmitir y crear una realidad paralela que nos aleja de los problemas cotidianos y de la rutina. Especialmente a partir del desarrollo del ecosistema tecnológico en la sociedad se crea un nuevo modelo de adquisición del conocimiento que da lugar a la conformación del individuo y a la creación de grupos o comunidades. Este nuevo modelo surge a partir de experiencias mediáticas relacionadas con el concepto de sociabilidad, vinculando a los múltiples individuos a través de las pantallas (Cáceres, 2012: 13).

De tal modo, con la entrada de los espacios digitales nace una nueva competencia básica: la habilidad de la identidad digital que implica un aprendizaje, una actitud colaboradora y participativa como uno de los núcleos fundamentales para la alfabetización mediática. Según Lara (2011), la identidad digital se identifica con aquella donde el usuario construye su propia identidad de dominio público, esta persigue la gestión y conocimiento de las consecuencias y beneficios de su impacto tanto para la audiencia como para el propio usuario. Este concepto adquiere una relevancia fundamental en la relación que se establece entre los medios audiovisuales y las redes sociales, espacios potencialmente controlables por los usuarios a quienes les corresponden la adopción de medidas que delimiten su privacidad en línea.

El gran impulso que ha conseguido Internet favorece la difusión de múltiples instrumentos comunicacionales, herramientas utilizadas para el diseño de productos mediáticos de los cuales se derivan diferentes modelos comunicativos, que influyen en miles de personas. Esta proliferación de las nuevas tecnologías podemos observarla en el uso masivo de las redes sociales, especialmente por parte de los jóvenes. Siguiendo a Espinar-Ruiz \& González-Río (2008), esta inmersión en el mundo virtual se ha quedado aislada en cuanto al acceso a Internet debido a que los usuarios realizan sus conexiones desde sus hogares; en este sentido inciden además en el uso de los juegos electrónicos como factor de iniciación digital.

En este ambiente cobra especial importancia la telefonía móvil utilizada hoy en día de forma casi general para acceder a la red. Por ende, contamos con una ingente cantidad de estudios que explican las nuevas transformaciones de la realidad, que estamos viviendo y donde los jóvenes, conocidos como los «nativos digitales», se convierten en el principal foco de interés debido al masivo uso de las nuevas tecnologías. La inclusión de los teléfonos móviles o "smartphones» están generando nuevas formas de relaciones interpersonales cuyo único fin es estar permanentemente conectado sin la necesidad de establecer una proximidad física entre los individuos (Pedrosa, 2012: 104).

Como conclusión, podemos destacar la recreación de fuentes y mensajes que están generando informaciones basadas en el montaje. Respecto a esta afirmación, «cada vez resulta más crítico exigirle al ciudadano una actitud de reflexión y una formación en criterios de verificación de la certeza de la información que utiliza, como actitud ante el aprendizaje a lo largo de toda su vida, ya que Internet se ha convertido en un medio tan natural que cuanto más se usa más confianza genera y menos se comprueba la fiabilidad de la información que se obtiene» (Lara, 2011).

Por ende, conviene destacar el escaso criterio con que cuenta la mayoría de individuos para contribuir en los procesos de intercambio de información y en sus formas de verificación. Todo ello se debe, en gran medida, a los nuevos entornos digitales que han conseguido potenciar nuevas formas de validación de la información basada en el número de «Me gusta» 0 «No me gusta» en el caso de «Facebook» o por ejemplo las etiquetas, retweets, seguidores e influencias como es en el caso de "Twitter», que aportan valor a los comentarios implicando que estas nuevas formas lleguen a ser consideradas como indicadores estándares de fiabilidad (González-Fernández, 2012: 25).

\section{La competencia mediática como forma de expresión social}

La realidad social y mediática actual centra el interés de formadores, académicos e investigadores que apuestan por la capacitación y la educación como el soporte básico para comprender la realidad digital actual. En este sentido, los profesionales de la información han de realizar una apuesta fuerte y contundente que favorezca el desarrollo de la actitud crítica por parte de la audiencia. Para ello desde la educación de los profesionales -las facultades de comunicación o las de relaciones públicas, entre otras- ha de tenerse en cuenta la necesidad de alfabetización mediática para el desarrollo de la autonomía crítica que permite el desarrollo y forja la capacidad para transmitir información, pensamientos o formas de expresarse adecuadamente.

Una alfabetización a la que hacía referencia Freire (1973) cuando se refería a la concientización que permite al sujeto salir de su posición de ignorancia, tarea que se complejiza en el contexto comunicativo actual donde resulta básico el lenguaje crítico dado que, supone la forma de «resolver el reto más abrumador a que nos enfrentamos en el siglo XXI» (McLaren y Kincheloe, 2007).

En definitiva, la correcta capacitación ha de ser desarrollada de forma uniforme por los agentes del proceso comunicativo quienes, más allá de cumplir con la normativa vigente deben tener presente la trascendencia de su trabajo y la importante repercusión que ejercen sobre la audiencia, tanto sobre los espectadores como sobre los productores e incluso sobre los «turistas conectados» (Garrido, 2014).

Asimismo conviene tener presente la transvalorización de valores a la que asistimos, un cambio protagonizado por la ingente cantidad de contenidos audiovisuales que aún no siendo reales se difunden como tales. Además de centrar el interés en cuestiones como la belleza, el cuerpo perfecto o el consumo de determinados productos que se presentan como «milagrosos», focaliza la atención, la comodidad e incluso la falta de responsabilidad que, en ocasiones se difunde como modelo a seguir. Todo ello conlleva a la necesidad de alcance de la ciudadanía mediática competente; para ello la Comisión Europea y el Parlamento (2009) ha realizado una serie de Recomendaciones 
Se trata de un conjunto de principios que centran el interés en la formación de la ciudadanía y el desarrollo de la actitud crítica. En este sentido, diferentes autores del panorama nacional e internacional tales como Eco (1993), Adorno (1969), Ferrés (2007) o García-Matilla (2003) se han encargado de analizar la situación mediática y de proponer medidas que contrarresten los efectos perniciosos de los contenidos audiovisuales difundidos, en ocasiones, sin el suficiente control.

Para ello conviene que la educación formal y la no formal trabajen en la misma línea: el desarrollo y la competencia mediática; por un lado es necesaria la formación desde las familias y las edades inferiores y en el ámbito académico se requiere de la actualización del currículum al nuevo paradigma formativo. El alcance de la ciudadanía mediática se propone partiendo del cultivo de la competencia mediática, que pese a no estar regulada entre las competencias básicas definimos según la digital y la audiovisual. La ciudadanía competente en medios se entiende como aquella que aúna las seis dimensiones propuestas por Ferrés en 2007, sí bien existen una serie de matices a tener en cuenta.

Siguiendo a Ferrés, el sujeto competente debe cultivar las dimensiones de la tecnología, el lenguaje, la recepción, la interacción, los valores y la estética. Se trata de habilidades cuyo alcance facultan al sujeto para comprender de forma eficaz los contenidos audiovisuales y le autorizan para producirlos. Al respecto de estas dimensiones, el Proyecto de Investigación de I+D+i sobre Competencia Mediática ha difundido diversos resultados que confirman que los diferentes colectivos de la ciudadanía -desde los 5 a los 18 años, el profesorado no universitario o los mayores de 55 años- desarrollan de forma irregular las seis dimensiones. Estos datos confirman por una parte, la necesidad de formación y por otra la vulnerabilidad de la ciudadanía en cuanto a la conformación de su opinión y comportamientos. Al mismo tiempo justifican el interés por el alcance de las dimensiones de la producción, los valores y la estética como las fundamentales a la hora de conformar la conciencia crítica.

Conviene resaltar la interesante asociación que Ferrés (2012), establece entre las dimensiones y los indicadores, es decir, vincula una capacidad a una destreza propia de la misma dimensión que capacita al sujeto para desarrollar la competencia mediática. Cada uno de los indicadores resulta relevante dado que muestra las habilidades mínimas que el ciudadano mediático ha de cultivar para poder analizar adecuadamente la realidad que recibe.

\section{El desarrollo de la conciencia crítica en el ecosistema comunicativo}

La forma de expresión autónoma en el ecosistema comunicativo se basa, como se ha indicado anteriormente, sobre tres de las dimensiones que propone Ferrés para el alcance de la competencia mediática. Se trata de las dimensiones que conforman la conciencia crítica a la que aluden diferentes pedagogos y educadores cuando sitúan la pedagogía crítica como una práctica que permite la lectura y decodificación de la realidad. Su alcance se propone a través del diálogo que favorece la comprensión del mundo y la realidad que se proyecta.

En este sentido, para los pedagogos críticos adquiere especial relevancia la idea de la educación como base sobre la que se forja el cambio social como motor para reducir las desigualdades de económicas o sociales, entre otras. En este sentido, la educación trata de incidir en la formación de buenos ciudadanos, capacitándolos para luchar por mejores formas de vida pública, formas comprometidas con los valores de la libertad, igualdad y justicia social. Para ello, exige una serie de modificaciones referidas a cuestiones políticas, éticas y al diálogo que supone un medio a través del cual se logra la autonomía y que favorece el desarrollo de sujetos libres, con capacidad para intervenir en la vida social de forma comprometida (Freire, 2008).

Esta pedagogía concibe el aprendizaje como un proceso continuo y constante que se desarrolla a lo largo de toda la vida, cuestión que se ejemplifica en el caso de la sociedad tecnológica y comunicativa actual. Un espacio donde, según se ha señalado en los principios de objetividad o realidad en ocasiones son vulnerados. Todo ello redunda en la necesidad de intérpretes críticos que cuentan con las herramientas mínimas que les capacitan para enfrentarse con posibilidades de resolver las dificultades que presenta un mundo cargado de riesgos (Aubert, 2009).

El desarrollo de la conciencia crítica se produce en la cultura de la participación y la responsabilidad tanto de la audiencia como de los medios y los profesionales de la comunicación. En este contexto, es necesaria la presencia de "prosumidores mediáticos» que definen García-Ruiz, Ramírez \& Rodríguez-Rosell, (2014: 16) como «productor y creador de mensajes y contenidos críticos, responsables y creativos». Un sujeto que sí bien cuida la calidad tecnológica, lingüística, estética e ideológica de sus mensajes, lo hace de forma consciente y autónoma, sin necesidad de ver coartada su libertad por la legislación ni por el rechazo impuesto desde cualquier medio que ejerza el control.

Esta última característica resulta fundamental dado que vivimos en la sociedad dialógica donde impera la democracia deliberativa que constituye según indica Segovia (2008: 49), «la única y verdadera forma de democracia abierta al cosmopolitismo y al multiculturalismo». Se trata de una democracia concebida según Cortina (2009), como «el régimen propio de ciudadanos, que se saben señores, y no siervos ni esclavos, autónomos y no heterónomos».

Además y en este sentido se identifica con una forma de vida que adquiere según Membreño (2004: 12), «su sentido real como praxis y no como retórica». Se trata de un proceso que se realiza gracias a la acumulación de las diferentes actividades diarias y a la interacción de diferentes sujetos, interacción que puede llevarse a cabo de forma presencial o virtual y que se apoya en la transmisión de información y en el proceso dialógico propio de las sociedades democráticas actuales. Su desarrollo se produce en un entorno deliberativo que permite a la comunicación considerada una de las piezas claves del sistema democrático propuesto: el dialógico. Un sistema que, ante todo, ha de ser incluyente. Además, entre sus funciones destaca la de protección de «los derechos de los más desprotegidos y vulnerables» que en este caso sería la audiencia quién, pese a contar con códigos deontológicos que todo profesional ha de respetar o con una importante legislación comunicativa, se convierte en víctima de los productores, que consideran a la información una mercancía, un bien de mercado 
En definitiva podemos definir el desarrollo de la conciencia crítica como el conjunto de habilidades que permite la expresión autónoma en la sociedad digital. Se trata de una facultad que permite la producción creativa de contenidos audiovisuales y su adecuada decodificación. Se identifica con la capacidad que permite el adecuado análisis de la realidad mediática y favorece la interacción de la ciudadanía en el actual ecosistema mediático.

\section{Discusión y conclusiones}

En la sociedad red a la que Bauman (2005) denomina sociedad líquida predominan, entre otros rasgos, la inmediatez y la emisión de la información que, en ocasiones se presenta sin contrastar. En este contexto digital resulta imprescindible que el sujeto sea capaz de analizar los contenidos; además de saber leer ha de poder interpretar la información de forma adecuada y autónoma. Para ello conviene el cultivo y alcance de las dimensiones, antes mencionadas, que le permiten actuar de forma crítica y responsable en la sociedad democrática y dialógica en la que vive.

En este contexto la omnipresencia mediática genera en la audiencia una necesidad imperiosa de consumir por un lado, dispositivos tecnológicos de última generación y por otro, contenidos e imágenes recientes. Este consumo, en ocasiones desmedido e irracional, se ve reforzado por la falta de madurez o la ausencia de criterio de los receptores; estos factores suponen algunos de los aspectos que intervienen tanto en la adquisición de contenidos de cualquier índole como en la posterior emisión de juicios y opiniones por parte de los sujetos.

En este sentido, Rainie y Wellman (2012) ya indicaban que estamos viviendo en constante cambio debido a una «triple revolución»; un cambio protagonizado principalmente por la presencia casi absoluta de Internet, las redes sociales y la comunicación móvil. Se trata de nuevas formas de expresión y difusión de la información que configuran el desarrollo de la cultura del «fast food». Además de configurarla llegan a generar una fuerte necesidad de consumo en el receptor e interfieren, de modo determinante, en su forma de actuar a la hora de comunicarse. Para ello se propone la educación mediática o educomunicación entendida como el conjunto de herramientas y estrategias que sirven para empoderar al sujeto y para contribuir a su formación y al desarrollo de juicios críticos y autónomos por su parte. Por otro lado, se alude a la creatividad y la interacción como factores que posibilitan el desarrollo de la conciencia crítica entendida como la capacidad de análisis propio de la realidad mediática.

Los numerosos cambios que el nuevo ecosistema mediático ha generado en nuestra sociedad han sido y son fácilmente constatables, en este sentido la constante necesidad del sujeto por estar continuamente informado desemboca en la denominaba "obesidad informativa», Puche (2013: 164). Se trata de una forma de incapacitar al individuo a la hora de digerir la información seleccionada que carece de una adecuada calidad. Una información cuya comprensión requiere al tiempo que justifica la formación; una formación que demanda, entre otros aspectos, el aprendizaje en materia digital y el desarrollo del conjunto mínimo de competencias y habilidades que favorecen la comunicación en este nuevo entorno interactivo. Pese a todo, la hibridación de contenidos y la proliferación de las múltiples pantallas y los nuevos contenidos aún no han conseguido sustituir al medio de comunicación por excelencia: la televisión. Un medio pionero que transmitía contenidos visuales y auditivos de forma simultánea y que, a lo largo de los años, desde los inicios hasta la actualidad ha experimentado diferentes modificaciones, variaciones que han ido surgiendo fruto de las múltiples necesidades que emergen. Las principales y más destacadas surgen al amparo de las nuevas necesidades por parte de los medios de comunicación y nacen para cubrir las múltiples formas de consumo que demanda la audiencia.

De lo expuesto hasta el momento, podemos deducir que las recientes tecnologías de la información se configuran, no sólo como herramientas de ocio y entretenimiento, sino también como instrumentos de aprendizaje de conocimientos. Las redes sociales, así como el uso de Internet a través de los teléfonos móviles, generan relaciones interpersonales logrando convertirse en el mejor agente socializador para los individuos.

La realidad implica y conlleva la necesidad de educar, una tarea que ocupa a los diferentes agentes formativos: familia, amigos, escuela y por supuesto los propios medios y los profesionales de la comunicación. Unos y otros han de favorecer el desarrollo de la actitud crítica para lograr un buen uso y el desarrollo de comportamientos acordes con los retos que presenta esta nueva sociedad «Multipantallas»; en definitiva surge la imperiosa necesidad de que la ciudadanía consumidora de los medios y los diversos contenidos audiovisuales se conviertan en buenos «prosumidores mediáticos» García-Ruiz, Ramírez \& Rodríguez-Rosell, (2014: 16). Según proponen las autoras los prosumidores mediáticos centran su labor en la producción y diseño de mensajes y contenidos creativos sin necesidad de dañar la calidad informativa.

Por último, se refuerza el valor de los continuos avances tecnológicos y su continúa repercusión en la conformación de la personalidad de los receptores. La sociedad de la comunicación y los medios continuará su evolución generando diversas repercusiones fruto de los múltiples avances; avances que requieren de una implicación clara por parte del ámbito educativo que debe encargarse de encarar adecuadamente no solo el desarrollo de las Tecnologías de la Información y la Comunicación (TIC) sino además la difusión de contenidos por parte de estas. En este sentido, debemos reflexionar sobre la necesidad de integrar no solo en los diferentes espacios sociales sino además en el aula a los medios y a las actividades digitales para una mejor formación. Una formación que se centra en el adecuado uso y comprensión de las nuevas tecnologías y contenidos audiovisuales. De forma general persigue el alcance de la «transmedialidad» entendida como el modo de transformar a los medios de comunicación en dispositivos tecnológico simultáneos que ayuden a la sociedad a adquirir las determinadas destrezas y competencias para un mejor uso de las nuevas tecnologías y las informaciones proporcionadas por éstas.

En definitiva y para digerir adecuadamente la información difundida como real a través de los diferentes medios y pantallas se propone el alcance de la competencia mediática que permite al sujeto, receptor activo o pasivo, desarrollar las habilidades que le facultan para comprender y producir mensajes, es decir para actuar como consumidor y productor activo de contenidos. 


\section{Bibliografia}

Adorno, T.W. (1969): Intervenciones. Nueve modelos de crítica. Caracas: Monte Ávila.

Alonso, G. T., \& Raigada, J. L. P. (2014). Multitarea, Multipantalla y Práctica social del consumo de Medios entre los jóvenes de 16 a 29 años en España. Actas - VI Congreso Internacional Latina de Comunicación Social.

Aubert, A., Duque, E., Fisas, M. \& Valls, R. (2009). Dialogar y transformar. Pedagogía crítica del siglo XXI. Barcelona: Graó.

Bauman, Z. (2005). Modernidad líquida. FCE: Argentina.

Cáceres, M. D. (2012). Telerrealidad y aprendizaje social. Revista ICONO14. Revista científica de Comunicación y Tecnologías emergentes, 5(1), 123-144. (http://dx.doi.org/10.7195/ri14.v5i1.375)

Campos-Freire, F. (2008). «Las redes sociales trastocan los modelos de los medios de comunicación tradicionales», Revista Latina de Comunicación Social, 63, 287-293. (DOI: 10.4185/RLCS-63-2008-767-287-293)

Canavilhas, J. (2011). El nuevo ecosistema mediático. Index. Comunicación: Revista científica en el ámbito de la Comunicación Aplicada, 1(1), 13-24.

Correa, R.I.; Guzmán, M.D. y Aguaded, J.I. (2000): La mujer invisible. Estereotipos de mujeres en los medios de comunicación. Huelva: Grupo Comunicar Ediciones.

Cortina, A. (2009). Las raíces éticas de la democracia. Valencia: Lluìs Palàcios.

Eco, U. (1993). Apocalípticos e integrados. Barcelona: Lumen.

Elola, J. (2010). «Los medios deben aparcar su arrogancia» Entrevista: el futuro del periodismo digital Rosental C. Alves, en El País. <http://www.elpais.com/articulo/reportajes/medios/deben/aparcar/arrogancia/elpepusocdmg/20100905elpdmgrep_5/Tes> 09/06/2015).

Espinar-Ruiz, E. y González-Río, M. J. (2008): «Jóvenes conectados. Las experiencias de los jóvenes con las nuevas tecnologías», RES. Revista Española de Sociología, (9). 109-122.

Fernández, P. E. (2013). Las audiencias en la era digital: interacción y participación en un sistema convergente. Question, 1(40), 68-82.

Ferrés, J. (2007). La competencia en comunicación audiovisual: dimensiones e indicadores. Comunicar, 29, 100-107.

Ferrés, J. \& Piscitelli, A. (2012). La competencia mediática: propuesta articulada de dimensiones e indicadores. <http://goo.gl/WnzTsO> (Consulta 27-06-2015).

Freire, P. (1973). Educación como práctica de la libertad. México: Siglo XXI.

Freire, P. (2008). Pedagogía da autonomía: saberes necesarios á prática educativa. Brasil: Paz e Terra.

García, M. T., Jiménez, J. L. T., \& Díaz, A. C. (2014). La investigación en comunicación en España: estado de la cuestión. Revista de la Asociación Española de Investigación de la Comunicación, 1(1).

García, R., Ramírez, A. \& Rodríguez, M.M. (2014). Educación en alfabetización mediática para una nueva ciudadanía prosumidora [Media Literacy Education for a New Prosumer Citizenship]. Comunicar, 43, 15-23. (DOI: 10.3916/C43-2014-01).

García-Matilla, A. (2003). Una televisión para la educación. La utopía posible. Barcelona: Gedisa.

Garrido, P. (2014). El turista conectado: de espectador a productor de contenidos. < http://goo.gl/EMIOLe> (Consulta: 24-05-2015)

Giones Valls, A.; Serrat i Brustenga, M. (2010). La gestión de la identidad digital: una nueva

habilidad informacional y digital. BiD: textos universitaris de biblioteconomia i documentació,

juny (24). <http://www.ub.edu/bid/24/giones2.htm> (Consulta: 16-04-2015).

González-Fernández-Villavicencio, N. (2012). Alfabetización para una cultura social, digital, mediática y en red. Revista Española de Documentación Científica, 35, 17-45. (DOI: 10.3989/redc.2012.mono.976)

Gutiérrez, E. C. (2011). Información Audiovisual, Multimedia y Educación. Etic@ net, 9(10), 9.

Lara, T. (2011). Alfabetizar en la cultura digital. Blog Tiscar.com. <http://tiscar.

com/2011/07/17/alfabetizar-en-la-cultura-digital/> (Consulta: 02/05/2015)

McLaren, P. \& Kincheloe, J.L. (2008). Pedagogía crítica. De qué hablamos, dónde estamos. Barcelona: Graó.

Membreño, S.A. (2003). Desarrollo humano, ética y ciudadanía en un mundo globalizado. Tegucigalpa: PNUD. 7-24.

Pedrosa, D. L. P., \& Maus, D. M. K. R. (2012). La nueva telefonía móvil y los cambios socioeducativos en los menores. Educación Y Medios De Comunicación, 1101.

Pérez-Tornero, JM (2008). La sociedad multipantallas: Retos Para La Alfabetización mediática. Comunicar, 31, 15-25. (DOI: 10.3916 / c312008-01-002).

Puche, J. S. (2013). Una propuesta de dieta digital: repensando el consumo mediático en la era de la hiperconectividad. Fonseca, Journal of Communication, 7, 157-175.

Segovia, J.F. (2008). Habermas y la democracia deliberativa. Una utopía tardomoderna. Madrid: Marcial Pons.

Toffler, A., \& Aleu, J. F. (1972). El «shock» del futuro. Barcelona: Plaza \& Janés.

Rainie, Lee y Wellman, Barry (2012): Networked. The New Social Operating System. Cambridge, MA: The MIT Press.

Ramonet, I. (2002). El poder mediático. Ciberlegenda, 7. (DOI: 10.5613/rzs.42.2.5)

Vecino, M. R. (2010). Desafíos de la televisión ante la consolidación del ecosistema digital. Ámbitos: Revista internacional de comunicación, (19), 25-42.

\section{Cómo citar este artículo en bibliografías - How to cite this article in bibliographies / references:}

CALDEIRO-PEDREIRA, M. C.; CASAS-MORENO, P. de (2016): "La competencia mediática como forma de análisis de la realidad transmitida". En Revista de la Asociación Española de Investigación de la Comunicación, vol. 3, número 6, pp. 77-83. 